\title{
АВТОТРОФНОСТЬ КАК ИМПЕРАТИВ СОЦИАЛЬНО-ЭКОНОМИЧЕСКОГО РАЗВИТИЯ РЕГИОНА
}

\author{
М. Л. Багайников \\ Байкальский государственный университет, г. Иркутск, Российская Федерация
}

\section{Информация о статье \\ Дата поступления \\ 12 мая 2017 г.}

Дата принятия к печати 30 мая 2017 г.

Дата онлайн-размещения 15 сентября 2017 г.

\section{Ключевые слова \\ Хозяйственная автотрофрность; устойчивое развитие региона; экономика региона; самообеспеченность региона}

\begin{abstract}
Аннотация
В статье раскрывается содержание категории «хозяйственная автотрофность» в увязке с ее биологическими и социальными составляющими и отмечается, что формирование автотрофного хозяйства способствует устойчивому эколого-экономическому развитию региона. Это особенно актуально в условиях абсолютного доминирования гетеротрофного способа хозяйствования, при котором природной среде зачастую наносится непоправимый вред. Кроме того, автотрофные принципы развития регионального хозяйства рассматриваются в сочетании с такими категориями, как «саморазвитие» и «самообеспеченность», которые представляются как взаимосвязанный синтетический комплекс, обеспечивающий стабильность функционирования системы «природа - хозяйство - население». Пространственное подразделение среды обитания человека - антропоэкосистема, включающая в себя природные, хозяйственные, экологические и культурные условия существования, в настоящее время подвергается негативному антропогенному воздействию, что угрожает устойчивости ее развития. Поэтому в статье отмечено, что к числу фракторов, обеспечивающих устойчивость антропоэкосистемы региона, следует отнести формирование автотрофрного хозяйства, предполагающего использование замкнутых производственных циклов и возобновляемых источников энергии.
\end{abstract}

\section{AUTOTROPHY AS AN IMPERATIVE OF SOCIO-ECONOMIC DEVELOPMENT OF THE REGION}

\author{
Mikhail L. Bagaynikov \\ Baikal State University, Irkutsk, Russian Federation
}

\author{
Article info \\ Received \\ May 12, 2017 \\ Accepted \\ May 30, 2017 \\ Available online \\ September 15, 2017

\section{Keywords} \\ Economic autotrophy; \\ sustainable development \\ of the region; regional \\ economy; regional self- \\ sufficiency
}

\begin{abstract}
The article is dedicated to the concept of «economic autotrophy» in conjunction with its biological and social components. The author notes that the development of autotrophic farming contributes to the sustainable ecological and economic development of the region. This is especially true in conditions of absolute dominance of the heterotrophic method of management, in which the natural environment is often irreparably damaged. In addition, autotrophic principles for the development of regional economy are studied in combination with such categories as «self-development" and "self-sufficiency", which are presented as an interrelated synthetic complex that ensures the stability of the functioning of the system «nature - economy - population». The spatial subdivision of the human environment - the anthropoecosystem, which includes natural, economic, ecological and cultural conditions of existence, is currently being subjected to negative anthropogenic influences, which threatens the stability of its development. Therefore, the author notes that among the factors that ensure the stability of the anthropoecosystem of the region, one should include the formation of an autotrophic farm, involving the use of closed production cycles and renewable energy sources.
\end{abstract}

Автотрофрность, в ее исходном естественно-научном понимании, есть вид трофической зависимости организма, когда он может существовать только за счет косного вещества и рассеянной энергии, не питаясь другими неделимыми жизнями. Автотрофность в широком смысле представляет собой способность человека как части биосферы 
повышать свою независимость от других форм жизни [1-3]. Вопросы перехода на автотрофный путь развития человека и человечества поднимались в творчестве Н. Ф. Федорова, А. Л. Чижевского, Н. А. Бердяева, В. А. Вернадского и др. [4-7]. Со временем актуальность вопроса формирования «автотрофнного человека» не только не понизилась, но, напротив, в контексте развития современной цивилизации неуклонно возрастает.

Современное человечество стремительно превращается в фрактор (угрозу) планетарного масштаба, что вызвало глобальные проблемы, связанные с нехваткой энергии и продовольствия. Это поставило цивилизацию перед жестким выбором: коренным образом изменить инфраструктуру общественного производства и систему ценностей (полномасштабный переход на автотрофный технологический сценарий развития) или погибнуть под тяжестью рыночного потребительства.

Выходом из сложившейся ситуации может стать максимально широкое применение автотрофного подхода к ведению хозяйства. При этом целесообразно было бы использовать принципы автотрофности хозяйственной деятельности не только в рамках отдельных государств, но и в планетарном масштабе. Однако на современном уровне развития цивилизации последнее невозможно, свидетельством чему служит то, что проводившиеся всемирные форумы, как то: Международная конференция $\mathrm{OOH}$ по проблемам окружающей среды (Рио-де-Жанейро, 1992 г.) и другие мероприятия (в том числе в рамках Римского клуба) - к существенным изменениям в сорере экологии и рационального ресурсопользования не привели. А. Д. Московченко по этому поводу замечает, что мы «живем не в XIX и не в XX веке, - наступил XXI век, век информационных, психо- и нанотехнологий, и здесь на первый план выходят проблемы биоавтотрофнокосмологического порядка, связанные с ближним и дальним Космосом» [2, с. 113]. То есть развитие продолжается по давно заложенной порочной траектории технологического развития в традиционно-гетеротрофных рамках, неминуемо связанной с самоуничтожением человечества, в то время как имеется альтернатива реализации автотрофного технологического сценария развития [там же].

Одним из основоположников данной теории по праву считается В. И. Вернадский, который в своих трудах неоднократно отмечал, что для достижения цели автотрофного развития человечества необходима эволю- ция биосфреры в ноосферу (вторую природу), т. е. в такое состояние биосферы, при котором главная роль отводится человеческому разуму [7]. Следовательно, «создание нового автотрофрного существа даст ему [человеку] доселе отсутствующие возможности использования его вековых духовных стремлений... » [8, с. 223]. Именно В. И. Вернадский осуществил проекцию проблемы автотрофности, придав этому термину социальный характер, т. е. перевел его из плоскости естественно-научной в социальную [1].

Наибольший интерес вызывает не столько способность человека существовать независимо от природы (что, естественно, в фризиологическом смысле невозможно), сколько вопросы повышения ресурсной независимости социальных и хозяйственных систем, а также их способности функционировать в замкнутых производственных циклах, подразумевающих переработку и потребление собственных отходов, что минимизирует вред, наносимый биосорере.

Под хозяйственной автотрофностью чаще всего понимают «использование возобновляемых источников энергии, замкнутые циклы производства, последовательное развитие и использование технологий, обеспечивающих процесс промышленного и сельскохозяйственного воспроизводства (связанных с ними инвестициями и потреблением) без ущерба окружающей среде и при сохранении биоразнообразия» [9, с. 117]. Гармонизация взаимодействия хозяйств и природной среды в связи с постоянно нарастающим антропогенным давлением становится все более актуальной проблемой, имеющей планетарный, региональный (межстрановой), национальный и локальный аспекты.

Деструктивные процессы в биосфере земли, вызванные хозяйственной деятельностью человека, который сам когда-то вышел из природной среды и до сих пор остается ее частью, поднимают вопросы соблюдения особой экологической этики и экологической эффективности хозяйственной деятельности. Можно отметить, что «при подобном порядке ценностей экологическая этика и экологическая эффрективность становятся системообразующими принципами экономики нового типа» [там же]. Концепция экологической эффрективности хозяйственной деятельности человека предполагает рост экологического потребления индивидуума без ущерба благосостоянию другого. Экологический императив в вопросах организации хозяйственной жизни может лечь в основу модернизации стратегии безопасного и устойчивого раз- 
вития, т. е. способствовать фоормированию новых подходов к решению вопросов обеспечения экологической безопасности.

Таким образом повышение экологической эффрективности, точнее экологическая полезность потребления, «есть ситуация отсутствия систематического рыночного риска в социально ориентированной экономике» [9, с. 118]. Основным ценностным ориентиром, параметром эфффективности в хозяйственной системе «экологической экономики», выступает экология, а центральное место в парадигме создания и функционирования экологически эффективного хозяйства занимают автотрофно-экологические инвестиции и потребление.

Автотрофно-экологический подход к функционированию социально-экономических систем, в том числе региональных, как один из подходов к проблеме устойчивого развития в настоящее время достаточно трудно реализуем в глобальном масштабе (поскольку требует политической воли и множества межгосударственных согласований). Однако отдельные подходы имеют перспективы для более широкого распространения в региональных хозяйственных системах, в рамках внутренних геоэкономических регионов, как наиболее гармонично организованных в пространственном аспекте. Поскольку структура последних представляет собой сложную взаимосвязь социальной, технической и природной сфер в их наиболее гармоничном сочетании, то формирование в них территориальных автотрофно ориентированных хозяйственных систем имеет, на наш взгляд, наибольшую вероятность реализации.

Региональная социально-экономическая система в широком смысле представляет собой триаду «природа - хозяйство - население», т. е. антропоэкосистему, которая может быть представлена как геоструктура, в которой взаимодействуют формирующие ее факторы: природа, население, культура, религия, социально-экономическое положение, хозяйство и т. п., т. е. то, что отсутствует в природных экосистемах. Порождением этой системы являются демографическое поведение людей, уровень здоровья, экологическое сознание, профессиональное предпочтение и уровень образования. Разомкнутость биогеохимических циклов, влекущая за собой накопление отходов, неизбежно приводит к качественным изменениям компонентов окружающей среды, а именно: те компоненты, которые в природной среде считаются возобновляемыми, в антропоэкосистеме переходят в категорию невозоб- новляемых (атмосферный воздух, пресная вода, почва). Отсюда напрашивается вывод о необходимости если не прекращения, то минимизации антропогенного воздействия на экосистемы микро-, мезо-, макро- и мегауровня. Достижение такого состояния антропоэкосистемами возможно только в случае обеспечения технической автотрофности в сочетании с территориальным совмещением сельских и городских антропоэкосистем в единую систему с замкнутым круговоротом веществ [10]. При существующем технологическом укладе формирование абсолютно замкнутых региональных систем практически невозможно. Однако необходимость продвижения в этом направлении неоспорима и должна обеспечиваться четко выстроенной последовательностью формирования соответствующих институтов автотрофно-экологического развития.

Близкой понятию «автотрофность», но не тождественной ему в региональном хозяйственном аспекте выступает категория «самодостаточность», т. е. способность к самообеспечению основными видами материальных благ, включающая в себя в том числе элементы регионального экономического протекционизма, осуществляемого в рамках действующих экономико-правовых норм. В отличие от понятия «автотрофнооть», «самодостаточность» главным образом охватывает организационно-управленческие аспекты развития региона, но вместе с тем неразрывно связана с его природной средой, определяющей природно-ресурсный потенциал. Известно, что понятие «регион» базируется на таких фрундаментальных категориях, как целостность, интегральность и самодостаточность [11]. Отсюда следует, что атрибут «самодостаточность», рассматриваемый в различных дефинициях, составляет одну из основ функционирования региона как сложного общественного феномена.

Наличие такого атрибута свидетельствует об обладании регионами страны (как административно-территориальными образованиями и неформальными территориальными, в том числе геоэкономическими структурами) свойством хозяйственной независимости. Однако автономия воли в принятии решений весьма условна и зависит от фрормального и неформального статуса каждого конкретного региона. В связи с этим можно отметить, что регионы России при исполнении своих внутренних функций обладают свойством независимости от внешних воздействий, за исключением одного или нескольких «избранных» системой направлений для осу- 
ществления органических связей с другими регионами, центром и остальным миром» [11, с. 98].

Хозяйственная автономия регионов современной России весьма условна и имеет множество оговорок, поскольку де-фракто они обладают ограниченными возможностями в вопросах самостоятельного развития. Однако в экономической плоскости отрицание атрибута независимости регионов может свести на нет все попытки проведения эфффективной региональной политики, поскольку сами регионы не будут иметь простора для маневра в принятии прежде всего хозяйственных решений. Потенциальную возможность вести относительно самостоятельную экономическую политику регионы имеют только в рамках единой государственной региональной политики, выстраивая систему взаимодействия с федеральным центром (вертикальные связи), с другими регионами (горизонтальные связи) и с внешним миром (международные связи). Однако для этого необходима смена идеологии и механизмов взаимоотношения между центром и регионами.

В существующей пространственной конфигурации регионы как хозяйственные единицы не отвечают современным требованиям, предъявляемым глобализирующейся экономической средой. Современные российские регионы по большей части «заточены» на решение определенных внутренних политических и хозяйственных задач и не готовы к новой глобальной геополитической и геоэкономической реальности. Сохранив множество хозяйственных элементов-реликтов, регионы в большинстве своем имеют невысокий потенциал устойчивого развития, в первую очередь ввиду отсутствия способности эффрективно встраиваться в существенно видоизмененную систему мирохозяйственных связей. Более того, сохраняющаяся тенденция хозяйственного развития российских регионов влечет за собой деградацию социальной (уровень жизни, демография) и природной среды.

Именно поэтому в основу регионального развития на современном этапе должны лечь концептуальные подходы, генетически произошедшие от концепта геоэкономического, наиболее полно учитывающего сочетание природных, хозяйственных и социальных факторов развития. Другими словами, концепт геоэкономический в региональном развитии есть вклад в развитие национальной экономики. Именно внутренние геоэкономические регионы России в современных условиях обладают наилучшими возможностями для развития международного сотрудничества, играя роль самостоятельного субъекта квазикорпорации. При определении и характеристике геоэкономических регионов традиционный экономико-географический подход заменяется на геоэкономический, учитывающий цивилизационно-политологический контекст таких территориальных структур, основанный на учете различий и сходности интересов множества исторически сложившихся общностей. То есть геоэкономические регионы часто представляют собой интернационализированные структуры, не ограниченные административными и политическими (формальными) границами, сорормированные на основе общностей этнокультурных, эколого-хозяйственных, транспортно-коммуникационных глобальных инфраструктур. Основой для вычленения геоэкономических регионов выступают естественные (природные) и искусственные коммуникации. К первым относят природные объекты, чаще всего гидросфрерные: бассейны рек, озер, морей и океанов; ко вторым - транспортно-коммуникационные объекты: нефте- и газопроводы, железные и автомобильные дороги, линии электропередач и т. п. Однако при этом такие регионы и их хозяйственные комплексы прежде всего призваны обеспечивать соучастие национальной экономики страны в глобальных воспроизводственных процессах. Такое позиционирование геоэкономических регионов обусловливает использование ими свойственных корпорациям принципов самообеспеченности, саморазвития и автотрофности, что обеспечивает более высокую устойчивость в условиях жесткого конкурентного взаимодействия (прежде всего глобального). Геоэкономические регионы, как правило, представляют собой целостные в хозяйственном и экологическом плане пространственные структуры, обладающие «врожденной» способностью к фрормированию самодостаточного хозяйства, что облегчает внедрение в них элементов автотрофного хозяйствования.

Деферент в сторону выстраивания территориями механизмов повышения самообеспеченности был вызван в том числе процессами глобализации, активизировавшими регионализацию как способ сохранения региональной идентичности в мире, где национальные границы становятся все более зыбкими, прозрачными. Более того, регионам государств отводится также важная роль в обеспечении национальной безопасности, когда они «выступают в качестве «буферной зоны» - выполняют функцию защиты обще- 
ственных отношений от негативных вызовов и угроз глобализационных процессов» [12, с. 93]. Таким образом, необходимость повышения уровня самообеспеченности регионов как адаптационного механизма в меняющейся экономико-политической среде становится все более очевидной, однако требующей соответствующего институционального оформления как на уровне регионов, так и на общегосударственном уровне, в рамках национальной политики регионального развития.

Основными компонентами развития институтов самообеспеченности и саморегулирования регионов как хозяйственных систем в контексте обеспечения их устойчивого и безопасного развития на фоне трансформации мирового геоэкономического пространства выступают:

1. Совершенствование федерального и регионального законодательства в части снижения чрезмерной зарегулированности процессов хозяйственного взаимодействия регионов как в вопросах развития межрегионального и международного сотрудничества, так и в вопросах взаимоотношений с федеральным центром. Кроме того, дальнейшее становление и развитие институтов правового регулирования регионального развития в сторону либерализации отношений в большей мере будет соответствовать принципам федеративного государственного устройства.

2. Совершенствование социальной и производственной инфраструктуры регионов. Данный институциональный аспект устойчивого регионального развития затрагивает такие вопросы, как развитие транспортной инфраструктуры, совершенствование комплекса региональных структур, обеспечивающих инновационное развитие (бизнес-инкубаторы, технопарки, инновационно-технологические центры ит. п.), и развитие других, в том числе социальных инфраструктур. Ценность инновационного развития экономики, фундаментом которого выступает региональная и национальная инновационные инфраструктуры, видится в современных условиях критически важной.

3. Совершенствование механизмов сохранения и использования потенциала региона - социального, экологического, экономического. Следует особо отметить то, что под экологическим потенциалом территории понимают потенциал природно-ресурсный, данный самой природой, пригодный для использования в настоящем и будущем. Формирование механизма сохранения и рационализации использования природно-ресурсного потенциала региона, а также их адекватная оценка являются главной составляющей устойчивого развития. Более того, наличие в регионе природных ресурсов, востребованных со стороны народно-хозяйственного комплекса страны, а также мирового рынка способствует его скорейшей интеграции в национальное и мировое экономическое пространство, что, в свою очередь, дает возможность эфффективно реализовать заложенный геоэкономический потенциал.

4. Совершенствование перераспределительного механизма национальной фискальной системы с целью увеличения доли налоговых поступлений в региональный и муниципальный бюджеты, уплачиваемых предприятиями малого и среднего бизнеса. В таком случае субъекты управления регионального и местного уровней будут заинтересованы во всестороннем содействии развитию местного предпринимательства, что неизбежно вызовет необходимость совершенствования институтов развития и обусловит продвижение в данном направлении.

Кроме того, определенный интерес применительно к региону вызывает категория «саморазвитие», которая традиционно относится к биологии и подразумевает умственное и фризическое развитие посредством самостоятельных усилий. Под саморазвитием региона понимается перевод его экономики на путь достижения состояния самосовершенствования и саморегулирования без практического внешнего воздействия. Это предполагает наличие известной автономии воли регионов в принятии экономических решений, естественно не нарушающей целостности единого экономического пространства страны. Также близкими являются такие понятия, как «самофинансирование», «самоуправление» и «самоокупаемость», каждое из которых имеет свои специфические особенности, но тем или иным образом составляет синтетическую категорию «саморазвитие региона» относительно либо «к определенным видам ресурсов (самоокупаемость, самофинансирование), либо к отдельным фуункциям (самоуправление)» [13].

Рассматривать вопрос становления региональных институтов самообеспечения и саморазвития без использования принципов хозяйственной автотрофрности будет неверным ввиду угрозы дальнейшего усиления рассогласованности функционирования социальной, природной и хозяйственной сред. Это негативно повлияет на устойчивость всей региональной триады «природа - хозяйство - население», поскольку лишь широкое применение «искусственных автотрофрных 
технологий разрешит экологические проблемы, снимет с человека тяжкий нравственный груз вины перед всем живым, даст возможность человечеству выжить в экстремальных условиях на путях будущего устойчивого развития» [14]. Очевидно, что экологическая составляющая выступает одним из параметров эфрфективности экономической системы с позиций качества управления, распределения ресурсов (рационального ресурсопользования) и эфффективной занятости населения [9]. То есть вышеупомянутую триаду «природа хозяйство - население» следует рассматривать как триединый комплекс (в том числе региональный), в котором дисбаланс в одной из составляющих (в природной, экономической или социальной системах) приведет к деструкции всей антропоэкосистемы.

К мероприятиям по повышению уровня автотрофности регионального хозяйства, а также по минимизации негативного антропогенного воздействия на природную среду с учетом географических и ландшафртных особенностей конкретной территории можно отнести:

- развитие альтернативной энергетики (возобновляемые источники энергии, как то: солнечная и ветровая), в том числе малых локальных гидроэлектростанций (микроГЭС);

- постепенное увеличение доли продовольствия, произведенного с помощью технологий органического сельского хозяйства, призванного, с одной стороны, повысить качество жизни населения путем увеличения предложения более качественной и здоровой сельскохозяйственной продукции, с другой - минимизировать негативное воздействие на природную среду в процессе осуществления производственной деятельности;

- создание мощностей по вторичной переработке отходов (производственных и бытовых) и их безопасной для природной среды утилизации как компонента реализации концепции замыкания кругооборота веществ в рамках территориальной антропоэкосистемы;

- создание на территории региона новых форм сельских поселений, известных в мировой практике как «экопоселения», создающихся в рамках реализации концепции «зеленой экономики», с гармонизацией взаимоотношений между социальной и природной средой;

- модернизация промышленности с целью ее перевода на производственные циклы замкнутого типа, что минимизирует негативное влияние на социоэкологическую среду территории и др.

В связи со всем вышеперечисленным региональный аспект фрормирования автотрофного типа хозяйства может получить реальное развитие прежде всего на уровне регионов. То есть регионы, благодаря своему относительно небольшому масштабу, что благоприятно сказывается на управляемости процессов, выступят своеобразными полигонами для отработки подходов к построению автотрофного хозяйства. Методологические подходы к формированию автотрофного регионального хозяйства после апробации в регионах могут быть использованы на национальном и международном уровнях при построении нового, более совершенного хозяйственного устройства, основанного на автотрофных принципах существования.

\section{СПИСОК ИСПОЛЬЗОВАННОЙ ЛИТЕРАТУРЫ}

1. Харламов С. Ю. Эволюция концепции автотрофрности человечества В. И. Вернадского / С. Ю. Харламов / / Научные ведомости Белгородского государственного университета. Сер.: Философия. Социология. Право. - 2008. — № 12 (52). - С. 196-201.

2. Московченко А. Д. Автотрофрная стратегия выживания / А. Д. Московченко // Вестник Российского философского общества. - 2011. - № 1. - С. 112-116.

3. Скачков А. С. Социально-философрский смысл общественной автотрофности и гетеротрофности в свете идей В. И. Вернадского / А. С. Скачков / / Омский научный вестник. - 2010. — № 1 (85). - С. 94-97.

4. Федоров Н. Ф. Философия общего дела / Н. Ф. Федоров. - М. : Эксмо, 2008. - 752 с.

5. Чижевский А. Л. Физические фракторы исторического процесса / А. Л. Чижевский. - М. : Кн. по требованию, 2012. - 76 с.

6. Бердяев Н. А. Избранные произведения / Н. А. Бердяев. - Ростов н/Д. : Феникс, 1997. - 544 с.

7. Вернадский В. И. Автотрофность человечества / В. И. Вернадский / / Русский космизм. Антология фрилософрской мысли / сост. С. Г. Семенова, А. Г. Гачева. - М. : Педагогика-Пресс, 1993. - 368 с.

8. Пономарев А. И. Концепция ноосферы В. И. Вернадского и проблемы экономической теории / А. И. Пономарев / / Истоки. Вопросы истории народного хозяйства и экономической мысли : сб. ст. / ред. В. А. Жамин, А. А. Баранов, Я. И. Кузьминов [и др.]. - М. : Экономика, 1989. - Вып. 1. - С. 222-223.

9. Мелокумов Е. В. Автотрофно-экологическая эффективность (полезность) и развитие альтернативной энергетики в проектировании экономики нового типа / Е. В. Мелокумов / / Вестник Московского государственного университета леса - Лесной вестник. - 2011. - № 2. - С. 117-124.

10. Глазачев С. Н. Устойчивость биосферы в условиях интенсивного антропогенного освоения природных систем / С. Н. Глазачев, В.И.Косоножкин / / Социально-экологические технологии. — 2012. — № 1. - С. 95-102. 
11. Шерстянкина Т. В. Инновационно-познавательные тенденции в определении самодостаточности российских регионов / Т. В. Шерстянкина // Вестник Бурятского государственного университета. - 2009. № 14. - C. 97-101.

12. Рудницкая А. П. Процессы регионализации в странах Европейского Союза: вызовы и тенденции / А. П. Рудницкая, Ю. А. Глинник // PolitBook. - 2016. - № 1. - C. 92-107.

13. Орешин В. П. Саморазвитие региона как основа демократизации общественных отношений / В. П. Орешин / / Транспортное дело России. - 2012. - № 6-2. - С. 58-59.

14. Московченко А. Д. Философия автотрофной цивилизации. Проблема интеграции естественных, гуманитарных и технических наук : учеб. пособие / А. Д. Московченко. - Томск : Том. гос. ун-т систем упр. и радиоэлектроники, 2010. - 263 с.

\section{REFERENCES}

1. Kharlamov S. Yu. Evolution of the Autotrophy Conception of Humankind by V.I. Vernadsky. Nauchnye vedomosti Belgorodskogo gosudarstvennogo universiteta. Seriya: Filosofiya. Sotsiologiya. Pravo = Belgorod National Research University Bulletin. Philosophy. Sociology. Law, 2008, vol. 28, no. 12 (52), pp. 196-201. (In Russian).

2. Moskovchenko A. D. Autotrophic Strategy of Survival. Vestnik Rossiiskogo filosofskogo obshchestva $=$ Bulletin of the Russian Philosophical Society, 2011, no. 1, pp. 112-116. (In Russian).

3. Skachkov A. S. Social and philosophical sense of public autotrophy and heterotrophy by the ideas of V. I. Vernadsky. Omskii nauchnyi vestnik = Omsk Scientific Bulletin, 2010, no. 1 (85), pp. 94-97. (In Russian).

4. Fedorov N. F. Filosofiya obshchego dela [The Philosophy of the Common Task]. Moscow, Eksmo Publ., 2008. 752 p.

5. Chizhevskii A. L. Fizicheskie faktory istoricheskogo protsessa [Physical Factors of the Historical Process]. Moscow, Kniga po trebovaniyu Publ., 2012. 76 p.

6. Berdyaev N. A. Izbrannye proizvedeniya [Selected Works]. Rostov-on-Don, Feniks Publ., 1997. 544 p.

7. Vernadsky V. I. Autotrophy of Humankind. In Semenova S. G., Gacheva A. G. (eds). Russkii kosmizm. Antologiya filosofskoi mysli [Russian Cosmism. Anthology of Philosophical Thought]. Moscow, Pedagogika-Press Publ., 1993. $368 \mathrm{p}$.

8. Ponomarev A. I. Vernadsky's Noosphere Concept and Problems of Economic Theory. In Zhamin V. A., Baranov A. A., Kuz'minov Ya. I. et al. (eds). Istoki. Voprosy istorii narodnogo khozyaistva i ekonomicheskoi mysli [Origins. Issues of History of Economy and Economic Thought]. Moscow, Ekonomika Publ., 1989, iss. 1, pp. 222-223. (In Russian).

9. Melokumov E. V. Autotrophic and Ecological Effectiveness (Usefulness) and Development of Alternative Energy in Designing a New Type of Economy. Vestnik Moskovskogo gosudarstvennogo universiteta lesa - Lesnoi vestnik = Moscow State Forest University Bulletin - Lesnoy Vestnik, 2011, no. 2, pp. 117-124. (In Russian).

10. Glazachev S. N., Kosonozhkin V. I. Sustainability of biosphere in the conditions of intensive anthropogenic development of nature systems. Sotsial' no-ekologicheskie tekhnologii = Social and Ecological Technology, 2012, no. 1, pp. 95-102. (In Russian).

11. Sherstyankina T. V. Innovative-cognitive trends in the definition of self-sufficiency of Russian regions. Vestnik Buryatskogo gosudarstvennogo universiteta = The Buryat State University Herald, 2009, no. 14, pp. 97-101. (In Russian).

12. Rudnitskaya A. P., Glinnik Yu. A. Regionalization processes in the European Union: challenges and trends. PolitBook, 2016, no. 1, pp. 92-107. (In Russian).

13. Oreshin V. P. Self development region as a basis democratization of social relations. Transportnoe delo Rossii = Transport business of Russia, 2012, no. 6-2, pp. 58-59. (In Russian).

14. Moskovchenko A. D. Filosofiya avtotrofnoi tsivilizatsii. Problema integratsii estestvennykh, gumanitarnykh i tekhnicheskikh nauk [Philosophy of Autotrophic Civilization. The Problem of Integration of Natural Sciences, Humanities and Technical Sciences]. Tomsk State University of Control Systems and Radioelectronics Publ., 2010. 263 p.

\section{Информация об авторе}

Багайников Михаил Логинович - кандидат экономических наук, доцент, докторант, кафедра бухгалтерского учета, анализа, статистики и аудита, Байкальский государственный университет, 664003, г. Иркутск, ул. Ленина, 11, e-mail: koterik@mail.ru.

\section{Для цитирования}

Багайников М. Л. Автотрофность как императив социально-экономического развития региона / М. Л. Багайников // Известия Байкальского государственного университета. - 2017. - Т. 27 № 3. - C. 359-365. - DOI: $10.17150 / 2500$ 2759.2017.27(3).359-365.

\section{Author}

Mikhail L. Bagaynikov - PhD in Economics, Associate Professor, candidate for Doctoral degree, Department of Accounting, Analysis, Statistics and Audit, Baikal State University, 11 Lenin St., 664003, Irkutsk, Russian Federation, e-mail: koterik@mail.ru.

\section{For Citation}

Bagaynikov M. L. Autotrophy as an Imperative of Socio-Economic Development of the Region. Izvestiya Baykal'skogo gosudarstvennogo universiteta $=$ Bulletin of Baikal State University, 2017, vol. 27, no. 3, pp. 359365. DOI: $10.17150 / 2500-2759.2017 .27$ (3).359-365. (In Russian). 